\title{
How primary teachers use games to support their teaching of mathematics
}

\author{
James Russo a, Leicha A. Bragg ${ }^{b}$, Toby Russo ${ }^{\circ}$
}

$\begin{array}{ll}\text { Received } & : \text { 1 September } 2020 \\ \text { Revised } & : \text { 22 December } 2020 \\ \text { Accepted } & : \text { 6 January } 2021 \\ \text { DOI } & : \text { 10.26822/iejee.2021.200 }\end{array}$

Corresponding author: James Russo,

Monash University, Wellington Rd, Clayton VIC, 3800, Australia.

E-mail: james.russo@monash.edu.

Phone: +61 399052791 .

ORCID: https://orcid.org/0000-0002-9855-7522

\section{b Leicha A. Bragg,}

Deakin University, Burwood Hwy, Burwood VIC, 3125, Australia.

E-mail: leicha.bragg@deakin.edu.au

ORCID: https://orcid.org/0000-0003-0579-4244

\section{c. Toby Russo,}

Spensley Street Primary School, 193 Spensley St, Clifton Hill VIC, 3068, Australia.

E-mail: Toby.Russo@education.vic.gov.au

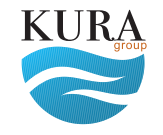

Copyright (C

www.iejee.com

ISSN: 1307-9298

(c) 2021 Published by KURA Education \& Publishing.

This is an open access article under the CO BYNC- ND license. (https://creativecommons.org/ licenses/by/4.0/)

\begin{abstract}
Mathematical games are widely employed by Australian primary school teachers to support mathematics instruction. Despite broad usage, prior research has not focused on the how and why games are employed from a teacher perspective. Australian primary school teachers $(n=248$ ) completed a questionnaire designed to probe their experience with mathematical games in the classroom, specifically; motivation for and frequency of game usage, game execution within lesson routines and structures, and, perceptions of the efficacy of games to achieve pedagogical objectives. Almost all the primary teachers self-reported playing mathematical games in their classrooms a minimum of once a week. Games were utilised in differing pedagogical capacities, for example, as a 'warm-up' exercise, to introduce new mathematical concepts, to consolidate skills and knowledge, and for fluency practice. Consistent with prior research, teachers viewed games as highly effective for engaging students in mathematics. Teachers also viewed games as being effective for developing all four proficiencies highlighted in the Australian Curriculum: Mathematics (ACARA, 2019); fluency, understanding, problem-solving, and reasoning. Interestingly, despite the burgeoning use of digital games, only two out of the 248 teachers surveyed mentioned a computer game or digital application as their favourite game to use in a mathematics lesson. A substantial majority of teachers nominated favourite games that involved minimal or no materials, in particular, playing cards and/ or dice, pen and paper, and oral games. Implications of these findings are discussed and future research directions are recommended. This study has taken steps towards deepening our mathematics educational community's understanding of primary teachers' use and experience of games.
\end{abstract}

\section{Keywords:}

Games, Teacher Perspectives, Pedagogical Approaches, Student Engagement, Mathematios Education 


\section{Introduction}

$\mathrm{T}$ word "game" brings to mind various interpretations. Mousoulides and Sriraman (2014) synthesised earlier work by Harvey and Bright (1985) and Oldfield (1991) to offer a comprehensive definition of a mathematical game. A mathematical game was defined as a pedagogical activity that:

- has specific mathematical cognitive objectives,

- [requires] students to use mathematical knowledge to achieve content-specific goals and outcomes in order to win the game,

- is enjoyable and with potential to engage students,

- is governed by a definite set of rules and has a clear underlying structure,

- involves a challenge against either a task or an opponent(s) and interactivity between opponents,

- includes elements of knowledge, skills, strategy, and luck, and,

- has a specific objective and a distinct finishing point. (p. 383, 384).

Findings from Bragg's (2012a, 2012b) research with upper primary students ( 9 - 12 year olds) supports the employment of games with these characteristics to promote mathematical cognitive growth and engage students. Other studies with similar definitions of games have found positive impacts of playing games on primary students' mathematical learning (Bright, et al., 1985; Cohrssen \& Niklas, 2019) and/or engagement in mathematics (Lindenskov \& Lindhardt, 2020; White \& McCoy, 2019). Indeed, a recent meta-analysis of mathematical games used in a Turkish educational context across all levels of education (pre-primary, primary, secondary and tertiary) incorporating 30 studies (4 journal articles, 26 dissertations) found that games had a medium positive impact on academic achievement compared with a variety of what were termed "traditional methods" of teaching mathematics (Turgut \& Temur, 2017, p. 196)

Given the considerable benefits of playing games, it is perhaps not surprising that instructional time devoted to game-related activities in the primary education context is both substantial and increasing (Heshmati et al., 2018). Yet, a search of the literature revealed there is a paucity of research into the frequency with which teachers employ games in the mathematics classroom. One exception is Russo and Russo's (2020) study involving 135 Australian early years primary teachers (Foundation, Year 1 and Year 2) participating in professional learning on teaching with challenging tasks. A single item in a pre-program questionnaire asked the frequency with which participants played games. Almost all early years teachers (98\%) who completed the questionnaire reported playing mathematical games at least once per week in their classrooms, whilst $85 \%$ of teachers reported playing games multiple times per week and over half (53\%) of teachers reported playing games 4-5 times per week. Surprisingly, given the evidence that most primary teachers use games multiple times per week to support mathematics instruction in class, it is curious how little prior research explores teachers' perceptions and usage of mathematical games in general (Heshmati et al., 2018).

The aim of this article is to broaden our current knowledge of how and why primary teachers use mathematical games in their classrooms. Specifically, we report on results from an online questionnaire of 248 primary teachers to address the research question:

- How are games used by primary teachers to support mathematics instruction?

We present the background literature organised into sections as follows: Mathematical games and the student learning experience, Games pedagogy, and Digital games.

\section{Background Literature}

\section{Mathematical games and the student learning experience}

For decades there has been a general acceptance by educators that mathematical games are beneficial for student learning. As early as the 1960s Dienes (1963) was advocating commencing mathematics lessons with games to tune students into the lesson. In the 1980s, Ernest (1986) wrote a rationale for the use of games citing the effectiveness of games to teach mathematics, particularly for: the acquisition and development of concepts; reinforcement and practice; developing problem-solving skills; and, motivation. Playing mathematical games offers an engaging way of developing problem-solving skills (Pintér, 2010), opportunities to improve students' social skills (Koay, 1996), foster mathematical reasoning (Olson, 2007), support differentiation (Buchheister et al., 2017), provide targeted instruction (Clarke \& Roche, 2010), and build connections between the home and school environment (Russo, et al., 2018).

Indeed, there is long-standing empirical evidence that playing games can lead to improved mathematical learning outcomes (Bragg, 2012b; Bright, et al., 1985; Swan \& Marshall, 2009), even for very young students (Elofsson et al., 2016; Ramani \& Siegler, 2008). For example, providing pre-school teachers with a suite of mathematical games, and a one-day workshop supporting them to use such games, improved the mathematical knowledge and skills demonstrated by their young students (Cohrssen \& Niklas, 2019). 
Using games has been noted to be effective for improving mathematical thinking across all levels of primary and secondary schooling, even if they do not explicitly target mathematical concepts. Cramer (2019) demonstrated that a board game can be used as a catalyst for exploring formal mathematical argumentation in upper secondary classrooms, positively impacting both the perceived competency and intrinsic motivation of students. Similarly, McFeetors and Palfy (2018) showed that engaging in commercial board games with logical structures provided opportunities for children to improve their capacity to reason mathematically.

Moreover, there is evidence that experiences designing mathematical games can support mathematical learning. Cody et al. (2015) instituted a yearlong study with 24 high performing upper primary students in the US that involved introducing six novel mathematics topics, adopting a repeated-measures design. For half of these topics, instruction involved explicit lessons, followed by collaborative problemsolving. For the other three topics, students were given an opportunity to create, and then play, mathematical games. Students created games that addressed the relevant mathematical learning focus. These games took the form of board, dice, or card games, and varied greatly in their content and complexity. The authors assessed performance on an achievement test linked to their state's curriculum standards, as well as students' perceptions of the lessons. Students' post-program performance on topics in the games condition was equivalent to their performance on the control condition topics, despite pre-program assessments indicating that the game topics were notably more difficult. Interestingly, student enjoyment, perceptions of their conceptual understanding, and overall motivation to engage in mathematics learning were similarly high in both conditions.

In a comprehensive series of studies examining the impact of mathematical games on student learning, Ramani and Siegler (2008; 2011) established that engaging in linearly numbered board games can improve students' whole number knowledge, and that such experiences can help reduce the mathematical performance gap between students in low-income and middle-income families prior to the start of school. The particular mechanics of the game were important for realising these gains. In particular, it was important that the board was numbered, presented in a linear representation (as opposed to circular), and that students were required to 'counton' as they played (Ramani \& Siegler, 2008; Siegler \& Ramani, 2009). Follow-up studies confirmed that the linear representation was particularly important for improving the capacity of students to accurately represent magnitudes on number lines, as well as developing their early arithmetic capability (although not necessarily for the development of counting or number naming; see Elofsson et al., 2016). Similarly, playing linear board games that included negative integers, and incorporating similar game mechanics to those advocated for by Ramani and Siegler (e.g., counting on; counting back), improved young school children's understanding of negative numbers (Bofferding \& Hoffman, 2019).

Additional evidence in support of the claim that mathematical games are effective for learning can be gleaned from the beliefs and attitudes of students themselves. White and McCoy (2019) undertook an action research project involving 24 fifth-grade students who played a series of mathematical games focused on interpreting co-ordinates and ordered pairs (e.g., battleships) across three consecutive mathematios lessons. These games were nondigital. The authors concluded that playing games improved students' knowledge of ordered pairs, and as well as their attitudes towards mathematics. White and McCoy's (2019) analysis of qualitative follow-up interviews with a subset of students revealed that these improvements in attitude were influenced by students cultivating a growth mindset (Dweck, 2015), the opportunity to strengthen problem-solving skills through working with another student, and the fact that the games themselves were highly engaging.

In further support of acknowledging students possessing positive attitudes towards playing games as an avenue for learning, Bragg (2007) found that prior to the game-play intervention three-quarters of the 121 upper primary students involved in her study agreed or strongly agreed with the statement "Maths games help me to learn maths", with only a small minority (9\%) disagreeing with the statement. Moreover, after spending eight sessions playing a challenging calculator based game focused on exploring multiplication and division of decimals, postintervention interviews revealed that the competitive game context motivated students to contend with demanding mathematical concepts beyond the local curriculum standards for their grade level, as they attempted to devise effective strategies for beating their opponent. However, using games alone is unlikely to be a panacea for learning mathematics. In the same study, Bragg (2012a) found that, although participating in an intervention involving games significantly improved student performance on an achievement test, a comparison group who undertook rich, problem-based activities focused on the same concept generated larger and more sustained improvements. This occurred despite students who played games being more likely to engage in relevant mathematical discussion than students who undertook rich, problem-solving activities (Bragg, 2012b). 


\section{Games pedagogy}

One of the proposed reasons why games might not be as effective for supporting learning as other pedagogical approaches is that excessive engagement in a game can be problematic, reducing the tendency to promote reflection and thus undermining potential learning (Harviainen \& Merilainen, 2019). It is in part for this reason that it is preferable when selecting games that the key mathematical ideas be central to gameplay, and for the game to be tested against the emergence of players applying heuristics disconnected from the core mathematics; that is, to prevent players 'gaming the system' (Heshmati et al., 2018, p. 779). The implication is that as students experience 'flow' (Csikszentmihalyi, 2014, p. 209) in the game, they are additionally contending with important mathematical concepts. To support this approach, Heshmati et al. emphasised the importance of utilising games which necessitate the player possessing a well-developed mathematical understanding of the relevant learning focus to be successful in the game. Heshmati and colleagues' (2018) naturalistic study monitored the introduction of two manipulative-based fraction games, Cover-up and Un-cover, in 14 fifth-grade classrooms. Although the fraction games analysed were used widely in mathematics classrooms, the authors concluded that the players were able to navigate play by referencing the different colour of the pieces rather than their fractional amount. Thus, little abstraction to the mathematical quantities was evident.

Another potential reason that games may result in less gains in learning compared with equivalent non-game activities, despite generating more mathematical discussion and on-task behaviour (Bragg, 2012a; 2012b), could be due to games leading to poorer quality mathematical interactions between the teacher and students. In the aforementioned study, Heshmati and colleagues (2018) analysed 70 video-taped mathematics lessons, some lessons involved the Cover-up and Un-cover games (14 lessons), whilst the remaining lessons included other learning experiences (e.g., worksheets, problemsolving activities) on the same topic, multiplication of fractions. The authors examined how the games were utilised, and compared the quality of teacher-student interactions across the games and non-games lessons. Games were almost exclusively used to review a concept and/or reinforce prior learning (13 lessons), rather than introduce or explore a new topic (1 lesson). The game segments in a lesson typically lasted for 15 to 20 minutes. The game-based lessons were associated with lower quality teacher-student interactions, with most interactions focused on game management, for example, turn-taking, game rules, or game progress, rather than the underlying mathematical concepts.
Rather than question the pedagogical value of games per se, Heshmati et al. (2018) concluded that teachers require explicit professional learning around how to employ games effectively. They suggest that part of this professional learning could involve more detailed instructional notes around implementing games, particularly in relation to teacher actions to elicit student mathematical thinking during play. "As the authors note: Ultimately, teachers are the ones who have to decide when and which games students play in their classrooms and how to make game playing a valuable classroom activity and learning experience" (Heshmati et al., 2018, p. 780).

Building on the notion that game mechanics are important in shaping the student learning experience (Ramani \& Siegler, 2008; 2011), it has been demonstrated that the design characteristics of a game can be systematically varied to achieve a particular pedagogical outcome. Nilsson (2007) investigated a small group ( $n=8)$ of Swedish seventhgrade students' reasoning through the experience of playing a purposefully structured probability game. The game involved students first distributing 24 or 36 counters across a game board labelled 1 to 12 and rolling two dice. Students removed a counter if its position on the game board was equal to the sum of the dice roll. The team to remove all their counters first was declared the winner. Drawing on principles of variation to encourage students to attend to the underlying mathematical structure, four different versions of dice were introduced to students across the data collection session. Although Nilsson (2007) was mainly concerned with how the game and its variations revealed and supported student thinking around probability, there were several instructional design characteristics worthy of note. First, Nilsson's (2007) study is a relatively rare example of exceptional care being taken to manipulate game mechanics to shape the student learning experience; a practice that is highly prevalent in the digital game educational literature (e.g., Lindström et al., 2011; Pareto et al., 2012), but relatively absent from the mathematical educational games literature. Specifically, Nilsson constructed the quantities on the dice and manipulated the order in which students engaged with different dice to encourage students to notice particular probabilistic phenomena. Second, the study utilised the power of competition and collaboration in deliberate ways. Allowing students to work in pairs enabled students' probability thinking to be illuminated, whilst encouraging students to refine their strategies through discourse with their teammate. Moreover, as Nilsson notes, competing against other teams was highly motivating, and incentivised students to engage more deeply with the mathematical ideas. 
Given the evidence that students' learning experience is impacted by the design characteristics of a game (Nilsson, 2007), it is noteworthy that inexperienced teachers find designing high quality games difficult. Pilten et al. (2017) undertook a study that involved 386 undergraduate pre-service teachers designing games for (hypothetical) Year 4 elementary students. The authors found that although participants tended to design games with compelling narratives that allowed for sufficient competition and challenge, they had more difficulty generating interactivity amongst players, articulating clear game rules, accurately representing mathematical concepts, and ensuring that gameplay promoted engagement with key educational objectives. Pilten et al. argued that supporting teachers to design educationallyrich games should be included as a focus of teacher education and professional learning. Perhaps the aspect of mathematics education in which the most attention has been paid to game design is in the area of digital games.

\section{Digital games}

Over the past two decades, there has been an increasing focus on digital games in the educational research literature. Beyond the field of mathematios education, recent reviews that have considered the educational value of game-based learning have focused overwhelmingly on digital games. Abdul Jabbar and Felicia (2015) identified 91 studies for inclusion in their systematic review of the educational outcomes associated with game-based learning, 18 papers specifically related to learning mathematical content. Although the scope of the review included both digital and non-digital games, only a single study identified in the review relied on a non-digital delivery platform (classified as a "board and cardbased game", p. 753). It is unclear whether this present focus of educational research on digital game-based learning aligns with the everyday usage of games by primary teachers in mathematics classrooms. Exploring this issue of teachers' usage of games, including digital and non-digital mediums, is one of the aims of the current study.

Some research into digital games has taken place specifically within a school-based context, and consequently informs our understanding of how digital games might support student learning. Pareto et al. (2012) evaluated how playing a computer game that required primary students to collaboratively engage with non-proportional virtual manipulatives and spatial representations of two- and threedigit numbers, impacted on students' conceptual understanding of Base-10 concepts. Forty-seven third grade Swedish students participated in the study. Students in the intervention group undertook seven 35-minute sessions involving the computer game over a nine week period as part of their mathematics instruction, whereas the control group received their regular classroom instruction (with the equivalent amount of instructional time) on the same topic. The game-playing group showed greater improvements in their conceptual understanding of Base-10 concepts over the control group, demonstrating that the game was efficacious. Further analysis revealed that students in the intervention group were more confident explaining mathematics to a peer, although there was no advantage of the intervention in terms of student attitudes towards mathematics. The authors attributed this later null finding to the global measure of attitudes towards mathematics employed in the study (e.g., questions such as "Do you think maths is boring or fun?"), noting that students may not have associated the game with "regular mathematics practice" (p. 742). The authors described the students in the game-playing group as being highly engaged in the game, enthusiastic to begin and reluctant to finish.

In summary, prior studies on games have indicated the effectiveness of games on students' mathematical understanding of concepts (Turgut \& Temur, 2017), but in some cases, these games were not as effective as well-crafted activities (Bragg, 2012b). Games have been employed in differing pedagogical approaches, yet researchers warn of the pitfalls of playing games without reflection or sufficient emphasis on key concepts (Heshmati et al., 2018; Pilten et al., 2017). Whilst there is research generally on digital games (Abdul Jabbar \& Felicia, 2015), focused research within the mathematics classroom is sparse. Notably, most of the research explores the impact of game interventions on students, and there is little known research enquiring about games from the teachers' perspective (Heshmati et al., 2018). The Methods section outlines how the current study attempts to address this gap in teachers' perspectives in the research.

\section{Method}

\section{Participants}

Two hundred and forty-eight teachers completed the questionnaire focused on how they use mathematical games in their classrooms. Participants were spread across all years of primary education in Australian classrooms: Foundation - Year 2, n= 78; Year 3 - Year 4, $n=63$; Year 5 - Year 6, n= 71; taught across multiple year level groups, $n=36$. As a group, they were relatively experienced primary school teachers, with a median time spent teaching of 10 years (mean $=13.2 ; S D=9.3$; Min = 1 year; Max $=51$ years . 


\section{iejee $\sqrt{2}$}

\section{Procedure}

The questionnaire was designed to be completed through an online survey platform Qualtrics. Online surveying was selected as a useful tool to reach a large cohort of teachers. Snowball sampling was used as a way of disseminating the questionnaire as widely as possible. Specifically, the first author circulated the survey link via email to 15 key informants based in three Australian states, as well as utilising social media (Twitter, Facebook) to directly recruit teacher participants. The only inclusion criterion was that a teacher was currently teaching in a primary context in an Australian school. Questionnaires were completed anonymously, and only completed questionnaires were considered for analysis. This research adhered to national ethics guidelines.

\section{Questionnaire}

In total, the questionnaire contained a mixture of four forced-choice and three open-ended items, as well as collecting demographic information (location, year level taught, number of years of teaching experience). In the current paper, we focused on three of the forced choice items and one of the open-ended items, specifically:

1. How frequently do you play maths games in your classroom? (forced-choice)

a. All the time (e.g., about 4-5 times per week)

b. Often (e.g., 2-3 times per week)

c. Sometimes (e.g., once per week)

d. Rarely (e.g., once per month)

e. Never

2. In which of the following ways do you use maths games? (forced-choice; frequency scale same as Item 1).

a. Outside of my maths lessons

b. As a warm-up activity in a maths lesson

c. As the main learning activity in a maths lesson

d. As the closure activity in a maths lesson

e. To support fluency practice

3. Maths games are effective for... (forcedchoice; 5-point Likert scale, ranging from strongly disagree to strongly agree)

a. engaging students in maths lessons

b. maximising on-task behaviour

c. generating rich mathematical discussions

d. differentiating for different performance levels

e. focusing students on important mathematical ideas

f. supporting connections between home and school

g. building procedural fluency

h. building conceptual understanding

i. building mathematical reasoning j. building problem-solving skills

4. Take a moment to reflect on your favourite maths game. Name and describe the game. How do you use the game in a lesson? Please provide as much detail as you can. (openended).

\section{Data analysis}

The frequency of responses to the survey data were analysed and are presented in tables in the following section. Teachers' open-ended responses were examined for references to the materials used to support their nominated favourite game.

We acknowledge that the data collection has limitations. The first is self-selection bias within online survey research (Thompson, et al. 2003); some participants are more likely to respond to survey requests than others. Therefore, the voices of those that do not respond to online survey requests are unheard. Second, apart from the demographic variables, little is known about the respondents beyond their self-reporting (Wright, 2006). There was no opportunity to check the veracity of their claims. These limitations underline the difficulty of collecting online survey data. Notwithstanding, a benefit of the online survey data was that it offered a snapshot of primary teachers' perspectives across the country. These perspectives are presented below.

\section{Results and Discussion}

In this section, the findings from the analysis on how 248 Australian primary teachers used games to support mathematics instruction are reported. The following four sub-sections are unpacked to understand more deeply the actions of teachers as facilitators of game-play: Frequency with which games are used in primary classrooms; How games are incorporated into classroom routines and lesson structures; Pedagogical aims teachers perceive mathematical games as being effective for achieving; and, Characteristics of highly valued mathematical games.

\section{Frequency with which games are used in primary classrooms}

Teachers were asked to report how frequently they played mathematical games in their classrooms. Five levels of frequency were provided, ranging from 'all the time' to 'never'. An indicative frequency corresponding to each descriptor was provided in parentheses (e.g., 'all the time'; 4-5 times per week) to elucidate the intention of these descriptors.

Table 1 summarises the frequency with which the entire sample of participating teachers played mathematical games in their classrooms, while Table 
2 provides the results by year level taught. Almost all teachers responding to our survey reported playing mathematical games at least once per week in their classrooms (98\%), whilst approximately one-third of teachers reported playing games all the time effectively every lesson. There was no correlation between teaching experience and the frequency teachers played games in their classrooms ( $r$ o $=0.02$, $p>$.05). Moreover, there were no notable differences in the frequency with which teachers played games across different year levels $\left[X^{2}(6,244)=1.457, p>.05\right]$.

It was concluded that, regardless of the year level they teach or their level of teaching experience, most primary school teachers reported playing mathematical games 'often' or 'all the time' in their classrooms. For parsimony, it is useful to combine these two categories 'often' and 'all the time' into a new descriptor, 'regularly'. Thus the term 'regularly' can be used to describe primary school teachers who reported playing mathematical games in their classrooms multiple times per week (i.e., at least twice per week). We will use this new descriptor 'regularly' for much of the remainder of our analysis, to distinguish between teachers who reported playing mathematical games multiple times per week and those teachers who reported using games less frequently.

Our results are consistent with the only other study of which we are aware that asked Australian primary school teachers about how frequently they employed games in their classrooms. Specifically, Russo and Russo (2020) reported that $85 \%$ of early years teachers (Foundation - Year 2) reported playing mathematical games regularly, compared with $79 \%$ of teachers in our study. This suggests that the snowball sampling methodology utilised in the current study did not result in teachers participating who were disproportionately inclined to play mathematical games in their classrooms, increasing the potential generalisability of the results reported here. In comparison, early years' teachers in our study were actually less likely to report playing mathematical games 'all the time' (35\%) compared with their counterparts in the Russo and Russo (2020) study (53\%).

\section{Table 1}

Frequency Teachers Reported Playing Mathematical Games

\begin{tabular}{lrr}
\hline & Frequency & Percent \\
\hline All the time (e.g., about 4-5 times per week) & 80 & $32 \%$ \\
Often (e.g., 2-3 times per week) & 116 & $47 \%$ \\
Sometimes (e.g., once per week) & 48 & $19 \%$ \\
Rarely (e.g., once per month) & 4 & $2 \%$ \\
Never & 0 & $0 \%$ \\
Total & 248 & $100 \%$ \\
\hline
\end{tabular}

\section{Table 2}

Percentage Frequency Teachers Reported Playing Mathematical Games by Year Level Taught

\begin{tabular}{|c|c|c|c|c|c|}
\hline & $\begin{array}{r}\text { F-Y2 Only } \\
(n=78)\end{array}$ & $\begin{array}{r}\text { Y3-Y4 Only } \\
(n=63)\end{array}$ & $\begin{array}{r}\text { Y5-Y6 Only } \\
(n=71)\end{array}$ & $\begin{array}{l}\text { Combination of levels } \\
\qquad(n=36)\end{array}$ & $\begin{array}{r}\text { Total } \\
(n=248)\end{array}$ \\
\hline $\begin{array}{l}\text { All the time (about } 4-5 \text { times per } \\
\text { week) }\end{array}$ & $35 \%$ & $35 \%$ & $28 \%$ & $31 \%$ & $32 \%$ \\
\hline Often (2-3 times per week) & $45 \%$ & $46 \%$ & $48 \%$ & $50 \%$ & $47 \%$ \\
\hline Sometimes (once per week) & $19 \%$ & $17 \%$ & $23 \%$ & $17 \%$ & $19 \%$ \\
\hline Rarely (once per month) & $1 \%$ & $2 \%$ & $1 \%$ & $3 \%$ & $2 \%$ \\
\hline Never & $0 \%$ & $0 \%$ & $0 \%$ & $0 \%$ & $0 \%$ \\
\hline Total & $100 \%$ & $100 \%$ & $100 \%$ & $100 \%$ & $100 \%$ \\
\hline
\end{tabular}

Note: Percentages in tables may not total 100 due to rounding 


\section{iejee $\sqrt{2}$}

How games are incorporated into classroom routines and lesson structures

Teachers were asked how they incorporated mathematical games into classroom routines and lesson structures. Results are reported in Table 3. Combining the categories 'all the time' and 'often', three-quarters of teachers reported using mathematical games regularly (i.e., multiple times per week) as a warm-up activity in a mathematics class. Using games as a 'warm-up' perhaps equated to a somewhat traditional conception of how primary teachers use games to support mathematics instruction (Bragg, 2006).

By contrast, slightly less than half the teachers in our sample reported regularly using mathematical games to support rich mathematical investigations (45\%), and one-third of teachers (33\%) regularly used games as the main learning activity in a mathematics lesson; although a large majority of teachers reported using games in these more substantive ways at least some of the time. Using a mathematics game outside of a mathematics lesson, or as a mathematics lesson closure, was less frequently reported by teachers.

It is noteworthy that almost all teachers (96\%) responding to our questionnaire reported using games in multiple ways to support mathematics instruction at least some of the time. This indicates that teachers understand the flexibility games offer as a pedagogical tool. Teachers incorporated mathematical games into their classrooms in a variety of ways, adopting at least two of these approaches at least once per week: using games as a 'warm-up', using games as the main learning activity, using games as a lesson closure, using games to launch a rich investigation or using games outside of the mathematics lesson. This variety of usage suggests that although teachers frequently used games as warm-ups, games were weaved into their instructional repertoire in a multi-faceted manner. It has been highlighted in the literature that using games in exclusively superficial ways (e.g., as rewards for early finishers, or as 'add-ons' to the lesson) is unlikely to support student learning, and that students benefit when teachers use games both for purposeful practice and introducing new mathematical concepts (Swan \& Marshall, 2009).

\section{Teachers' pedagogical aims when using mathematical games}

In general, teachers indicated that mathematical games were highly effective for achieving the pedagogical aims outlined in the survey (see Table 4). There is evidence that teachers thought games were most effective for engaging students in mathematics lessons, with all except one teacher agreeing with this statement, and $82 \%$ of teachers indicating that they strongly agreed with this statement. This finding is consistent with the research literature indicating that student engagement is an advantage offered by games over other potential activities (Attard \& Curry, 2012; Bragg, 2012a; Kim et al., 2017). Moreover, building on other strengths of games noted in previous research, approximately 9 in 10 teachers in our study agreed or strongly agreed that games were effective for supporting differentiated instruction (Buchheister et al., 2017), maximising on-task behaviour (Bragg, 2012a), and focussing on important mathematical ideas (Pintér, 2010). Interestingly, a similar proportion of teachers endorsed the capacity of games to generate rich mathematical discussion, despite mixed evidence for this in the literature (Bragg, 2012b; Heshmati et al. 2018). In particular, Heshmati and colleagues' suggested that games often lead to superficial interactions between teachers and students, due to the teacher focusing more on managing the game than probing students' mathematical thinking.

\section{Table 3}

Percentage Frequency of Ways Teachers Use Mathematical games to Support Mathematics Instruction

\begin{tabular}{|c|c|c|c|c|c|}
\hline & $\begin{array}{r}\text { All the time } \\
\text { (4-5 times per } \\
\text { week) }\end{array}$ & $\begin{array}{r}\text { Often } \\
\text { (2-3 times per } \\
\text { week) }\end{array}$ & $\begin{array}{r}\text { Sometimes } \\
\text { (once per } \\
\text { week) }\end{array}$ & $\begin{array}{c}\text { Rarely } \\
\text { (once per } \\
\text { month) }\end{array}$ & Never \\
\hline $\begin{array}{l}\text { Outside of my maths lessons } \\
\text { (e.g., end of the day before } \\
\text { packup) }\end{array}$ & $3 \%$ & $16 \%$ & $48 \%$ & $25 \%$ & $9 \%$ \\
\hline $\begin{array}{l}\text { As a warm_up activity in a } \\
\text { maths class }\end{array}$ & $30 \%$ & $45 \%$ & $19 \%$ & $4 \%$ & $1 \%$ \\
\hline $\begin{array}{l}\text { As the main learning activity in } \\
\text { a maths class }\end{array}$ & $4 \%$ & $29 \%$ & $53 \%$ & $13 \%$ & $1 \%$ \\
\hline $\begin{array}{l}\text { As the closure activity in a } \\
\text { maths lesson }\end{array}$ & $2 \%$ & $14 \%$ & $40 \%$ & $34 \%$ & $9 \%$ \\
\hline $\begin{array}{l}\text { To support rich mathematical } \\
\text { investigations }\end{array}$ & $11 \%$ & $34 \%$ & $38 \%$ & $14 \%$ & $3 \%$ \\
\hline
\end{tabular}




\section{Table 4}

Percentage of Teachers Agreeing/Strongly Agreeing with the Effectiveness of Games for Achieving Various Pedagogical Aims

\begin{tabular}{|c|c|c|}
\hline & $\begin{array}{r}\text { Combined } \\
\text { Agree or } \\
\text { Strongly Agree }\end{array}$ & $\begin{array}{r}\text { Only } \\
\text { Strongly Agree }\end{array}$ \\
\hline Engaging students in maths lessons & $100 \%$ & $82 \%$ \\
\hline Maximising on-task behaviour & $88 \%$ & $49 \%$ \\
\hline Generating rich mathematical discussions & $92 \%$ & $50 \%$ \\
\hline Differentiating for different performance levels & $89 \%$ & $56 \%$ \\
\hline Focusing students on important mathematical ideas & $90 \%$ & $45 \%$ \\
\hline Supporting connections between home and school & $71 \%$ & $32 \%$ \\
\hline Building procedural fluency & $86 \%$ & $45 \%$ \\
\hline Building conceptual understanding & $90 \%$ & $43 \%$ \\
\hline Building mathematical reasoning & $91 \%$ & $50 \%$ \\
\hline Building problem-solving skills & $91 \%$ & $50 \%$ \\
\hline
\end{tabular}

By contrast, the least endorsed aim was 'supporting connections between home and school'. However, it is notable that even for this least endorsed item, 7 in 10 teachers agreed that games were an effective means of supporting connections between home and school, with one-third of teachers strongly agreeing with this statement.

Another interesting aspect of the data presented in Table 4 is that it offers support for the assumption that teachers do not exclusively view games as being effective for building procedural fluency. In fact, teachers tended to view games as supporting the development of all four proficiencies highlighted in the Australian Curriculum: Mathematics equally (ACARA, 2019), including reasoning and problem-solving. Other authors have provided examplesillustrating how games can be effective for developing the mathematical proficiencies beyond procedural fluency, including mathematical reasoning (Olson, 2007), conceptual understanding (Clarke \& Roche, 2010) and problemsolving (Pintér, 2010). Taken collectively, the views of teachers in our study are highly consistent with the argument that playing a game should be equivalent to engaging in meaningful mathematics (Swan \& Mitchell, 2009) that builds mathematical proficiencies.

\section{Characteristics of highly valued mathematical games}

Most teachers (85\%; 211 out of 248) described a favourite mathematical game for which the game materials could be discerned from their description. In instances where more than one game was described, the first game they outlined was the one analysed. Results are displayed in Table 5.

Table 5

Materials Involved in Teachers' Favourite Games

\begin{tabular}{lrrr}
\hline Materials & Frequency & Percent & Example \\
\hline Dice and/ or playing cards & 126 & $60 \%$ & Greedy Pig; Dice Cricket \\
Pen and Paper Only & 36 & $17 \%$ & Mastermind; Bingo \\
Oral Games & 24 & $11 \%$ & Buzz; 21. \\
$\begin{array}{l}\text { Custom Cards (Sourced/ Created by } \\
\text { teacher) }\end{array}$ & 9 & $4 \%$ & I am, who is? \\
Commercial Games & 5 & $2 \%$ & Prime Climb \\
'Real World' & 5 & $1 \%$ & Chocolate, Music \\
Digital Games & 3 & $1 \%$ & Wishball \\
Counters & 3 & Bullseye \\
\hline
\end{tabular}

Note: $n=211 ; 37$ teachers did not respond to this item or provided a general response that could not be further classified (e.g., "multiplication games"). 


\section{iejee $\approx$}

Approximately $60 \%$ of teachers who responded to this item described a game involving playing cards or dice (126 out of 211). The next most frequently described games were those requiring no additional equipment beyond pen and paper, and in some instances a template constructed by the teacher (17\%). Games involving verbal interactions only (described as 'oral games') were a favourite of approximately 1 in 10 teachers. Interestingly, only a tiny fraction of teachers nominated a computer game or app (1\%).

Additional analysis of the data revealed that whilst one-quarter of the games described involved some sort of physical activity, or bodily engagement on behalf of the players (e.g., students standing up and sitting down in Greedy Pig), only $4 \%$ of games involved students or the teacher interacting with a digital technology in any capacity (e.g., digital game, calculator, random number generator, interactive number chart, supportive software). To summarise, overwhelmingly primary teachers' favourite games appear to be a low technical experience, requiring minimal equipment beyond cards, dice and, on occasion, a printable template.

These results contrast with the literature, where the research into digital games to support mathematics learning is substantial and in fact notably more prevalent than non-digital games (Abdul Jabbar \& Felicia, 2015). There are many reasons why digital games might lend themselves to being the focus of educational research vis-à-vis non-digital games, such as: the provision of a highly controlled-environment, the precision with which game mechanics can be modified systematically, opportunities to provide learners with immediate feedback regarding student accuracy, the efficiency at which data can be collected and analysed, and students familiarity with, and interest in, digital games (Divjak \& Tomić, 2011). However, to the extent that research in education should both reflect and inform current teaching practices, and in light of the views expressed by teachers in our study, the privilege given to investigating digital games in the research literature can be viewed as problematic.

\section{Conclusions and Implications}

In this paper an account was presented of primary teachers use of games to support mathematics instruction. The findings from this study provide quantitative evidence that Australian primary teachers are frequent users of mathematical games in their classrooms, and employ games in a variety of pedagogical practices, beyond a reward or time-filler. As long-time advocates of the benefits of games for students' mathematical learning, we are heartened by these findings.

Many of the favourite games mentioned by teachers require few or no materials (e.g., cards and dice), and have relatively simple rules (e.g., greedy pig, mastermind, buzz). Due to the frequency with which mathematical games are used among teachers and the preference for simple games, there may be an opportunity to create a central depository and/or to provide additional professional learning to bolster the pedagogical repertoire of teachers. Ideally, these professional resources would focus on games that require few inputs, provide ideas on how these games might be adapted to suit the differing needs of students, and possibly include suggestions about how to transform games into rich investigations to deepen mathematical reasoning (Russo \& Russo, 2020). In addition, there are perhaps opportunities for universities to include a greater focus on mathematical games in pre-service preparation courses and, in turn, to help maximise the educational value of games in Australian classrooms. Pre-service teachers would benefit from exploring the role of games to support differentiation and to deepen mathematical thinking, and to build their confidence in game selection and modification.

Beyond the previously noted limitations of relying on online questionnaire data, it is important to note the data from the current study was collected in late 2019 which was prior to the COVID-19 pandemic impacting Australia. This additional contextual characteristic is important, as it is likely that if the questionnaire had of been administered in 2020 after online and remote teaching was being implemented across the country, some of our findings would have been different. For instance, we note the lack of focus on digital games in the questionnaire responses may at first glance seem somewhat surprising, given the proliferation of digital games usage in Australia and globally (Abdul Jabbar \& Felicia, 2015). The growth in online teaching and remote learning in response to the COVID-19 pandemic leads us to question what opportunities for online game play might have been taken up by teachers over the past year that will be further incorporated into mathematics instruction in the future. Potentially, teachers who are catering for students learning online and remotely will utilise digital games more readily than their non-digital counterparts. Another potential impact of the COVD19 pandemic may have been the further utilisation of mathematical games by educators as a means to strengthen home-school connections. Although a majority of teachers recognised building homeschool connections as one of the aims of playing mathematical games, it was the least endorsed aim. However, due to their inherent interactivity (be it cooperative or competitive), it is more likely many Australian adults engaged in mathematical games with their child/ren during remote learning periods in 2020 and beyond. 
which games are employed in the mathematics classroom, and provides further support for the notion that games can engage students (Kim et al., 2017), support differentiated instruction (Buchheister et al., 2018), maximise on-task behaviour (Bragg, 2012a), allow students to explore important mathematical ideas (Pintér, 2010) and generate rich mathematical discussion (Bragg, 2012b). However, there remains a need for more focused research aimed at exploring the mechanisms through which games may lead to these outcomes, as well as providing opportunities to better understand some of the subtler research findings. For instance, an overwhelming majority of respondents in our study highlighted the effectiveness of games in promoting rich mathematical discussions, but the type of interactions and their role in supporting mathematical learning are unclear. Previous research indicates that whilst games may promote rich peerto-peer mathematical discussions (Bragg, 2012b), they may lead to more superficial mathematical interactions between the teacher and students (Heshmati et al., 2018). Consequently, endeavouring to better understand both the role games play in promoting mathematical dialogue between students, between teacher and students, as well as students and their family, and the net effect of games on the quality of mathematical interactions in and beyond the classroom seems important. Future mathematical games research must incorporate study designs that shed light on these and other complexities.

\section{References}

Abdul Jabbar, A. I., \& Felicia, P. (2015). Gameplay engagement and learning in game-based learning: A systematic review. Review of Educational Research, 85(4), 740-779. https:// doi.org/10.3102/0034654315577210

Attard, C., \& Curry, C. (2012). Exploring the use of iPads to engage young students with mathematics. In J.Dindyal, L. P. Cheng, \& S. F. Ng (Eds.), Mathematics education: Expanding horizons (Proceedings of the 35th annual conference of the Mathematics Education Research Group of Australasia) (pp. 75-82). Singapore: MERGA

Australian Curriculum, Assessment and Reporting Authority (ACARA) (2019). Australian Curriculum: Mathematics. Retrieved from https://Www. australiancurriculum.edu.au/f-10-curriculum/ mathematics/key-ideas/

Bofferding, L., \& Hoffman, A. (2019). Children's integer understanding and the effects of linear board games: A look at two measures. The Journal of Mathematical Behavior, 56, 100721. https://doi. org/10.1016/j.jmathb.2019.100721
Bragg, L. A. (2006). 'Hey, I'm learning this'. Australian Primary Mathematics Classroom, 11(4), 4-7.

Bragg, L. (2007). Students' conflicting attitudes towards games as a vehicle for learning mathematics: A methodological dilemma. Mathematics Education Research Journal, 19(1), 29-44. https:// doi.org/10.1007/bf03217448

Bragg, L. A. (2012a). The effect of mathematical games on on-task behaviours in the primary classroom. Mathematics Education Research Journal, 24(4), 385-401. https://doi.org/10.1007/s13394-0120045-4

Bragg, L. A. (2012b). Testing the effectiveness of mathematical games as a pedagogical tool for children's learning. International Journal of Science and Mathematics Education, 10(6), 1445-1467. https://doi.org/10.1007/s10763-0129349-9

Bright, G. W., Harvey, J. G., \& Wheeler, M. M. (1985). Learning and mathematics games. Journal for Research in Mathematics Education, Monograph Number 1, 1-189. https://doi. org/10.2307/749987

Buchheister, K., Jackson, C., \& Taylor, C. (2017) Maths games: A universal design approach to mathematical reasoning. Australian Primary Mathematics Classroom, 22(4), 7-12.

Clarke, D., \& Roche, A. (2010). The power of a single game to address a range of important ideas in fraction learning. Australian Primary Mathematics Classroom, 15(3), 18-23.

Cody, K. J., Rule, A. C., \& Forsyth, B. R. (2015). Mathematical game creation and play assists students in practicing newly-learned challenging concepts. Creative Education, 6(14), 1484. https://doi.org/10.4236/ce.2015.614149

Cohrssen, C., \& Niklas, F. (2019). Using mathematics games in preschool settings to support the development of children's numeracy skills. International Journal of Early Years Education, 27(3), 322-339. https://doi.org/10.1080/09669760.2 019.1629882

Cramer, J. (2019). Games as a means of motivating more students to participate in argumentation. In Eleventh Congress of the European Society for Research in Mathematics Education (No. 10). Freudenthal Group; Freudenthal Institute; ERME. 


\section{iejee}

Csikszentmihalyi, M. (2014). Toward a psychology of optimal experience. In Flow and the foundations of positive psychology (pp. 209-226). Netherlands: Springer. https://doi. org/10.1007/978-94-017-9088-8_14

Dienes, Z. P. (1963). An Experimental Study of Mathematics Learning, Hutchinson, New York.

Divjak, B., \& Tomić, D. (2011). The impact of game-based learning on the achievement of learning goals and motivation for learning mathematicsliterature review. Journal of Information and Organizational Sciences, 35(1), 15-30.

Dweck, C. (2015). Carol Dweck revisits the growth mindset. Education Week, 35(5), 20-24.

Elofsson, J., Gustafson, S., Samuelsson, J., \& Träff, U. (2016). Playing number board games supports 5-year-old children's early mathematical development. The Journal of Mathematical Behavior, 43, 134-147. https://doi.org/10.1016/j. jmathb.2016.07.003

Ernest, P. (1986). Games. A rationale for their use in the teaching of mathematios in school. Mathematics in School, 15(1), 2-5.

Harviainen, J. T., \& Meriläinen, M. (2019). Educational gamification: Challenges to overcome and to enjoy. In Neo-Simulation and Gaming Toward Active Learning (pp. 553-560). Springer, Singapore. https://doi.org/10.1007/978-981-138039-6_51

Harvey, J. G. \& Bright, G. W. (1985). Basic math games. Palo Alto, California: Dale Seymour Publications.

Heshmati, S., Kersting, N., \& Sutton, T. (2018). Opportunities and challenges of implementing instructional games in mathematics classrooms: Examining the quality of teacher-student interactions during the cover-up and un-cover games. International Journal of Science and Mathematics Education, 16(4), 777-796. https:// doi.org/10.1007/s10763-016-9789-8

Kim, S., Chang, M., Deater-Deckard, K., Evans, M., Norton, A., \& Sumar, Y. (2017). Educational games and students' game engagement in elementary school classrooms. Journal of Computers in Education, 4(4), 395-418. https:// doi.org/10.1007/s40692-017-0095-4

Koay, P. L. (1996). The use of mathematical games in teaching primary mathematics. The Mathematics Educator, 1(2), 172-180.
Lindenskov, L., \& Lindhardt, B. (2020). Exploring approaches for inclusive mathematics teaching in Danish public schools. Mathematics Education Research Journal, 32, 57-75 https:// doi.org/10.1007/s13394-019-00303-z

Lindström, P., Gulz, A., Haake, M., \& Sjödén, B. (2011). Matching and mismatching between the pedagogical design principles of a math game and the actual practices of play. Journal of Computer Assisted Learning, 27(1), 90-102. https://doi.org/10.1111/j.1365-2729.2010.00380.x

McFeetors, P. J., \& Palfy, K. (2018). Educative experiences in a games context: Supporting emerging reasoning in elementary school mathematics. The Journal of Mathematical Behavior, 50, 103125. https://doi.org/10.1016/j.jmathb.2018.02.003

Mousoulides, N. \& Sriraman, B. (2014). Mathematical games in learning and teaching. In S. Lerman (ed.), Encyclopedia of Mathematics Education, (pp. 383-385). https://doi.org/10.1007/978-94007-4978-8

Nilsson, P. (2007). Different ways in which students handle chance encounters in the explorative setting of a dice game. Educational Studies in Mathematics, 66(3), 293-315. https://doi. org/10.1007/s10649-006-9062-0

Oldfield, B. J. (1991). Games in the learning of mathematics: Part 1: A classification. Mathematics in School, 20(1), 41-43.

Olson, J. C. (2007). Developing students' mathematical reasoning through games. Teaching Children Mathematics, 13(9), 464-471.

Pareto, L., Haake, M., Lindström, P., Sjödén, B., \& Gulz, A. (2012). A teachable-agent-based game affording collaboration and competition: evaluating math comprehension and motivation. Educational Technology Research and Development, 60(5), 723-751. https://doi. org/10.1007/s11423-012-9246-5

Pilten, P., Pilten, G., Divrik, R., \& Divrik, F. (2017). Evaluation of mathematical game design skills of pre-service classroom teachers. International Electronic Journal of Elementary Education, 10(2), 255-264. https://doi.org/10.26822/iejee.2017236120

Pintér, K. (2010). Creating games from mathematical problems. Primus, 21(1), 73-90. https://doi. org/10.1080/10511970902889919

Ramani, G. B., \& Siegler, R. S. (2008). Promoting broad and stable improvements in low-income children's 
numerical knowledge through playing number board games. Child Development, 79(2), 375394. https://doi.org/10.1111/j.1467-8624.2007.01131.x

Ramani, G. B., \& Siegler, R. S. (2011). Reducing the gap in numerical knowledge between lowand middle-income preschoolers. Journal of Applied Developmental Psychology, 32(3), 146159. https://doi.org/10.1016/j.appdev.2011.02.005

Russo, J., \& Russo, T. (2020). Transforming mathematical games into investigations. Australian Primary Mathematics Classroom, 25(2), 14-19.

Russo, J., Russo, T., \& Bragg, L. A. (2018). Five principles of educationally rich mathematical games. Australian Primary Mathematics Classroom, 23(3), 30-34.

Siegler, R. S., \& Ramani, G. B. (2009). Playing linear number board games-but not circular onesimproves low-income preschoolers' numerical understanding. Journal of Educational Psychology, 101(3), 545. https://doi.org/10.1037/ a0014239

Swan, P. \& Marshall, L. (2009). Mathematical games as a pedagogical tool. In CoSMEd 2009 (3rd International Conference on Science and Mathematics Education Proceedings), pp. 402406, Penang, Malaysia.

Thompson, L. F., Surface, E. A., Martin, D. L., \& Sanders, M. G. (2003). From paper to pixels: Moving personnel surveys to the Web. Personnel Psychology, 56(1), 197-227. https://doi.org/10.1111/j.1744-6570.2003. tb00149.x

Turgut, S., \& Temur, Ö. D. (2017). The effect of gameassisted mathematics education on academic achievement in Turkey: A meta-analysis study. International Electronic Journal of Elementary Education, 10(2), 195-206. https://doi. org/10.26822/iejee.2017236115.

White, K., \& McCoy, L. P. (2019). Effects of game-based learning on attitude and achievement in elementary mathematics. Networks: An Online Journal for Teacher Research, 21(1), 1-17. https:// doi.org/10.4148/2470-6353.1259

Wright, K. B. (2006). Researching internet-based populations: Advantages and disadvantages of online survey research, online questionnaire authoring software packages, and web survey services. Journal of ComputerMediated Communication, 10(3). https://doi. org/10.1111/j.10836101.2005.tb00259.x 